\title{
Making sense of methods - a conversation about qualitative research in library and information studies
}

\author{
Edward F. Abbott-Halpin, Antony Bryant
}

\begin{abstract}
Currently there is an embarrassment of riches with regards to the range of research methods appropriate for library and information studies (LIS); including qualitative and quantitative methods as well as 'mixed methods'. All of this provides a rich body of resources for researchers, but this abundance also has a downside since it can also result in confusion and perplexity amongst researchers as they plan their investigative studies. Contributions such as this special issue are welcome opportunities to resolve and ameliorate this situation, and so in our contribution we seek to address some of these issues in the form of an interchange between two researchers with interests that include, but are not limited to, research in LIS. Between us we have a wide range of publications, as well as 80 plus PhD completions, many of which fall under the heading of LIS - broadly conceived. In particular we would claim specific expertise in Grounded Theory [Bryant] and Action Research [Abbott-Halpin]. Our aim is to seek clarification of some of the key methodological issues; although we realize that this is unlikely to provide any definitive outcome, it may assist those seeking guidance on these matters.
\end{abstract}

\section{Dialogue}

AB: It might be best to start by addressing the confusion that arises from the wide range of terms and their differing uses that occur in discussion on research methods. I think it is important that people understand 'research' itself as a verb at

\section{Authors}

Antony Bryant is Professor of Informatics at Leeds Beckett University, with extensive experience in supervising and examining doctoral students across a range of disciplines; also in teaching and writing on research methods and research practice.

Email: a.bryant@leedsbeckett.ac.uk

Edward Abbott-Halpin is Professor of Social \& Human Rights Informatics at Leeds Beckett University. He has wide experience in supervising and examining research students, and as an active research manager.

Email: e.abbott-halpin@leedsbeckett.ac.uk 
least as much as a noun - i.e. an activity - which leads immediately to consideration of what is involved in doing research: a series of activities that incorporate planning and investigation, as well as dissemination and dialogue within one or more research communities. The issue of the approach that is taken then has to encompass this wide range of activities. I deliberately use the rather vague term 'approach', because it is at this point that terminological confusion arises as different authors use one or more terms such as 'strategy', 'method', 'methodology', 'tool', 'technique', and so on.

E A-H: Confusion seems to be an apt description; there is too often a lack of clarity and words relating to research are used interchangeably. At the same time, surely with the plethora of good and well written books on undertaking research it is impossible to conflate terms or be confused. Is this confusion therefore from failure to engage with the literature, failure to understand it, or is there a confusion found within the various texts which compounds this problem?

Having said that there really ought not to be confusion, there might be reasons that compound this. Within some subjects or disciplines, within some geographical or cultural settings, there are still assumptions that for research to be valid it must have a hypothesis, be quantitative, and conform to a positivist approach; there are $\mathrm{PhD}$ students who arrive with this presumption and academics who find it hard to move beyond this perspective. So might confusion also be compounded by these prejudices that favour such approaches: in these cases Grounded Theory or Action Research are perhaps unrecognised or misunderstood, along with other qualitative approaches, and therefore add to this confusion.

Thus far there is no mention of research philosophy, which again is the subject of many research texts, and again offers the unwary the opportunity to apply this term as interchangeable with other research terms. But really, the question has to be put again, should there be this confusion or failure to understand accurately and explain precisely what we mean or intend in undertaking research?

AB: I doubt that any standardized definitions will ever be established, and indeed would argue that it would be a mistake to try to do this; but anyone writing on the topic should ensure at least aim for consistency in their own use of terms something that $\mathrm{I}$ have tried to do in my recent book, albeit with a warning to readers that we all fall short of our own admonitions (see Bryant, 2017, chapters 1 $\& 2$ ). Moreover I must point out that what you term the plethora of texts on the topic probably results in more confusion rather than less, given the many ways in which different authors define and relate these and other key terms.

You have picked up on my omission of 'research philosophy', and that was deliberate. In the 1980s, as we first developed courses on Research Practice, I spent a fair amount of time explaining ideas about research philosophy, different paradigms, and so on. Similarly I always tried to ensure that our PhD students discussed these issues in their theses, regardless of their topic and approach. But I now counsel that dealing with these issues - ontology, epistemology, research paradigm, research philosophy, and so on - can be a fraught and unsatisfying 
experience for all concerned. Philosophers continue to wrestle with these complexities, and so it is perhaps unrealistic to expect $\mathrm{PhD}$ students to do so with any success.

More importantly, I have found that there is almost no relationship between the research philosophy expressed by researchers as their guiding principles and the actual outcomes of their research. I know that there is a vast array of research philosophies, and that the distinctions are in many cases substantive, but broadly I adhere to Richard Rorty's clear and direct view that the main distinction is between the position that 'truth is discovered' - e.g. positivism - and the alternative that 'truth is made' - e.g. constructivism. With regard to the Grounded Theory Method [GTM], for instance, this distinction is encapsulated in the title of Glaser and Strauss' founding text The Discovery of Grounded Theory (1967), and Charmaz' later, canonical work Constructing Grounded Theory (2006, 2014). In reviewing a whole host of GTM-oriented PhD theses, journal papers, and other outputs, however, I have found many examples of people professing to follow a positivist line, one with which I profoundly disagree, but whose research outcomes - models, theories, and the like - are profound, rigorous, and convincing; similarly there are some who take a constructivist position, often referencing Charmaz' and my work, whose outcomes are lacking in precisely these features. As a consequence I can sympathise with those who opt to stay well away from substantive discussion of such issues.

The issue of what counts as 'proper' research is, however, more critical. As you know we have had several cases where our students think it imperative to have a hypothesis from the outset, and in some cases they have persevered with this throughout their research, leading to successful outcomes. Others have either started from a different position, or altered their views as things have developed, but we have always sought to ensure that doctoral students are aware of the alternatives, specifically GTM since this was and remains the exemplar for research starting from a more open-minded position. So in some cases students have changed their initial ideas about their research strategy and followed a more open-ended approach; others have found themselves at an impasse once their research is underway and have had to make major changes to their research approach and plans. With due acknowledgement to Glaser and Strauss, who introduced the term 'theoretical sensitivity' in their GTM writings in the 1960s, I have coined the term 'methodological sensitivity' which can be defined as the skill or aptitude required by researchers in selecting, combining, and employing methods, techniques, and tools in specific research contexts; something that is particularly important as research projects develop and may demand repositioning and re-orientation (Bryant, 2017, 36).

I would now argue that methodological sensitivity needs to be more widely understood and acknowledged, particularly amongst the gate-keepers - the journal editors and reviewers, examiners and evaluators in general. Again we can point to instances where researchers have submitted work that has evoked reviews along the lines of 'where is the hypothesis?', and comments that indicate either that the reviewer is unaware of a whole host of rigorous and well-tested alternatives, or takes the view that these methods are not up to scratch in one way or another, and as you intimate this is particularly the case for qualitative methods such as GTM, 
Action Research, and their ilk. There are, of course, many examples of poor research using these methods; but there are also at least as many instance of bad research using 'approved' ones, including quantitative methods.

E A-H: I can agree that there might not be absolute consensus on definitions, but would contend that a high level of consistency is vital; how else can a research community know that they are researching their topic in a scientific manner, or how else can we follow other people's research, use it and learn from it? It would perhaps be useful to look at the approach you take to one or two of the key arguments you put forward in your own work.

'Research Philosophy' was certainly fundamental to key research texts of the 1980's and perhaps the 1990's in general, and also I believe in teaching research with the LIS community. I have reviewed the key texts that I used back then, and have been looking at our own library holding on research methods for librarians, the concept appears strongly in many of them. Pickard (2007, xv) for example offers a research hierarchy, which is as follows: Research Paradigm, Research Methodology, Research Method, Research Technique, and Research Instrument. In its way this hierarchy, which I believe originates from the work of Guba and Lincoln (1998), is helpful to the researcher and reflective of the approaches generally found in research. In this case it is used in establishing 'some standard research terms and the connections between those terms' (Pickard, 2007, xv). There is, however, a paradox for us, especially those of us who tend to use more qualitative research approaches. Surely we all need to have a knowledge of 'research philosophy' and to be able to exhibit it. If we do not then surely we will be accused of not being 'scientific', though I readily acknowledge the angst and confusion this can create for PhD students or less experienced researchers. The response is often a re-statement of tried and tested formulae, largely derived from worthy texts, but without real relevance to the research being undertaken.

I would concur with you on Rorty's position that the main distinction is between 'truth is discovered' - e.g. positivism - and 'truth is made' - e.g. constructivism. I would also agree with you in respect of the confused positions offered by $\mathrm{PhD}$ students, some of whom we have shared, but this also extends to examiners on occasions, especially when faced with a GTM study. The issue of what is 'proper research' certainly is critical. I am particularly minded of a student who was sponsored and had an additional supervisor from his own country where there was an orthodoxy in approach that required a hypothesis and a questionnaire, and this persisted throughout the $\mathrm{PhD}$, almost causing significant problems as the study progressed. It was evident in this case that GTM was not a familiar approach, even though it was equally evident that the approach yielded far better data and analysis than the more traditional approach could; it simply was not to be regarded as proper research! I think you draw a valuable distinction between theoretical sensitivity and methodological sensitivity, this seems to be borne out in recent work by Chu (2015) in the work "Research methods in library and information science: A content analysis" where she suggests that

The LIS field is maturing in terms of research method selection and application in that a greater number and wider variety of research methods are used in all the 
research publications this study examines. All the methods reported in the 1162 scholarly publications in a sense constitute a toolbox of research methods. Scholars are no longer limited to the research methods traditionally applied in LIS explorations (e.g., questionnaire and historical method). Researchers can instead choose research methods from this expanded toolbox according to their study objectives. (Chu, 2015, 40)

Chu also stresses that her research indicates the need to increase knowledge of and use of qualitative methods in LIS research. Perhaps it is therefore appropriate to look at approaches such as GTM and Action Research, but also different data gathering and analysis tools and techniques.

AB: With regards to research philosophies, we can agree that all researchers should have some grasp of their variety and distinctions, regardless of the specific approach they choose to take; also that researchers should clearly indicate their own position in reporting on their work. It can then be left to others - supervisors, examiners, and assessors - to evaluate the extent to which the researcher's assumptions influenced or constrained the research itself. The metaphor of a toolbox is a useful one, although it is important to note that Chu's examples include more than what might be described as 'tools' - i.e. the historical method, and questionnaires, the latter being a prime example of a tool, but it also encompasses techniques for designing and administering the questionnaire. With regard to the former, the phrase 'historical method' trips readily off the tongue, but I am not convinced that there actually is one historical method (see Bryant $e t$ al., 2013).

It is certainly important that researchers develop an appreciation of the range of available options, and do not simply take one or other as a default because that is all they know. Furthermore as their research develops they need to be aware that it might be necessary to consider a possible change of direction and overall strategy in the light of what has transpired in their work. Again we can both point to examples of $\mathrm{PhD}$ students who have done exactly this, with successful outcomes every time. (Bryant, 2017, chapter 19 consists of verbatim accounts by four of my $\mathrm{PhD}$ students, illustrating many of these issues.)

It is important that in considering the available options - or tools - researchers are open to all possibilities. When Glaser and Strauss wrote The Discovery of Grounded Theory in the mid-1960s, one of their key concerns was to counter the widespread assumption that only quantitative, hypothesis-based research counted as real research, with qualitative research a poor relation, at best offering some preparatory outcomes for the real deal. It would be nice to think that this debilitating misconception has now disappeared, but unfortunately it is all too alive and well. Moreover although the outcome of a quantitative study can indicate the extent to which some issue is significant or influential, it is often the outcome of a qualitative study that has given guidance on what needs to be measured, and, most critically, how practice might then be improved as a consequence. As William Bruce Cameron observed, "Not everything that counts can be counted, and not everything that can be counted counts" (1963): Einstein chalked this on the board in his office in Princeton. 
Now with regard to GTM and Action Research [AR], here are two methods that were specifically developed as challenges to the accepted ways of doing academic research. Glaser and Strauss developed GTM as a rigorous and systematic alternative to the deductive, hypotheses-based ones prevalent in the social sciences in the USA in the 1960s. AR emanates as a distinct method from the work of Kurt Lewin (1946) who was concerned that research and conceptual development encompass critical and effective interventions, and provide the basis for a partnership between all those involved in the endeavour - not simply a set of activities centred on the researchers. This specifically challenged the view that research was done from a disinterested and distanced position. For Lewin effective research should aim for and potentially lead to improvement and enhancement for those involved in the context of the research as part of their daily lives; researchers could not take a remote and neutral position, but should actively engage - hence the development of variants of AR such as Participative AR, and Community AR. Lewin was also concerned to dissipate the supposed dichotomy between 'theory' and 'practice', elegantly summarized in his adage: "There is nothing as practical as a good theory."

AR itself has continued to flourish since Lewin's early work, with the many variants comfortably co-existing to their mutual benefit (see the excellent overview in Reason and Bradbury, 2013). Unfortunately this has not been the case with GTM, where Glaser took exception to the later work of Strauss, particularly that co-authored with Julie Corbin in the 1990s (Strauss and Corbin, 1990, 1998). Later in that decade Kathy Charmaz articulated a further variant - Constructivist Grounded Theory $(2006,2014)$ - explicitly responding to some of the clearly identified weaknesses in GTM, again drawing criticism from Glaser who continues to defend what he terms 'Classical GT' against anything he sees as a 'remodelling' of the method. Whatever the pros and cons of this may be, the downside is that researchers claiming use of GTM have of necessity to 'take sides' or at the very least steer a path between or around the variants on offer. The result is that what ought to be rightly regarded as a valuable and highly innovative contribution to the armoury of methods has become mired in claims about what constitutes 'genuine' GTM. This is further exacerbated by a widespread, and illfounded, scepticism regarding the method itself, often based on a few examples of misuse of the method - something that is, of course, prevalent across all research, but seems to be particularly potent with regards to GTM.

Since the publication of Charmaz' Constructing Grounded Theory a body of GTM writing has grown and established a far more robust basis for the method. There is still a good deal of misunderstanding and hostility to the method, but this is gradually dissipating - not before time - in the light of these developments. The Sage Handbook of Grounded Theory (Bryant and Charmaz, 2007a) illustrates the wide range of articulations and applications of the method, including the ways it draws on constructivist and Pragmatist epistemologies.

I would argue that GTM offers a number of aspects of good practice, regardless of the method or approach taken by a researcher, in addition to the specific aspects of the method itself; I can outline each of these topics in turn, with specific reference to issues around LIS research, and I am sure you can also offer further insights with regard to AR. 
The first of these is 'open-mindedness'; sometimes misleadingly stated in terms of starting one's research 'with no preconceptions'. Ian Dey clarified the distinction between these statements with the observation that "an open mind is not the same as an empty head" $(1993,65)$ : The former is a key to all good research, the latter, even if it were actually possible, would be highly inadvisable. Glaser and Strauss, in articulating the innovative characteristics of GTM, were particularly keen to offer a rigorous and practical alternative to research that developed from hypotheses derived - using deduction - from existing theories; hence their advocacy of a method that began from a far more exploratory and open basis. A starting point that has sometimes been misunderstood or poorly expressed - 'no preconceptions' - but which has now been more than adequately clarified by many authors including Charmaz and myself, both separately (Charmaz, 2006, 2014; Bryant, 2017) and in concert (Bryant \& Charmaz, 2007b); so there should be no grounds for continuing with these misconceptions. For LIS researchers this should be seen as offering a justifiable basis for research that starts from an interest in a general issue or context (see Alemu et al. (2015) and MacLennan (2012) for recent examples; also Mansourian (2006) for a general overview), but does not seek at the outset to articulate a specific research question or set of hypotheses. Clarification and focus becomes an important research output, reached after initial investigation, and in many cases arrived at in an unexpected manner. All researchers should be open to being surprised by their findings, but for qualitative researchers in general, and specifically for GTM researchers, this is a common experience; attested to from the 50 plus PhDs which I have either supervised or examined.

Whichever variant of GTM is used, the research process starts from and maintains a close interaction with the data. It is now widely understood that in general the process of 'coding' can proceed in two distinctly different ways; either allocating the data to prepared categories, or analysing the data and only then starting to develop the categories. The former approach is the older and more traditional one, with the categories themselves derived from existing theories. Glaser and Strauss, however, offered an alternative approach with the researchers gathering data, from which the relevant and appropriate codes and categories are then derived. In other words the identification and characterization of the codes is dependent on the analysis of the data itself - i.e. grounded in the data. This can sound highly disconcerting to doctoral students and other early-stage researchers, but in practice they find themselves quickly developing codes, and grouping these into more abstract categories; then using these as the basis for later stages of their research.

A third aspect of GTM, not widely discussed in the founding works of the 1960s, but thereafter a key aspect, is memo-making. Glaser discusses memos and memomaking in Theoretical Sensitivity (1978), and from that date the issue has been clearly central to GTM. The practice itself, however, should be encouraged across all forms of research, and to a large extent is encompassed by the concept of a research log or reflective diary. An understanding of memos in the context of GTM, however, is crucial since it focuses on the ways in which the practice of memo-making embodies both self-reflection and conceptual development in the research process. LIS researchers should be encouraged to undertake this range of activities regardless of their chosen strategy. In practice this serves three purposes; 
1) documenting their initial ideas about the research project, 2) describing the ways in which their grasp of methods, tools, and techniques develops as they progress, and 3) their thoughts on their findings from early insights through to drafts of later statements, chapters, or submissions to journals. In practice $\mathrm{PhD}$ students often produce a mix of all three, with their thoughts on methods and so on being predominant in the early and middle stages of their work; then such topics gradually falling away, as they develop their concepts and findings in the latter stages. For researchers working as a team, memos can serve as ways in which each member can document their own ideas, and then be introduced as contributions to the team, along with other members' memos, with further memos then documenting the ways in which disparate views are reconciled or resolved. It is unfortunate that Glaser and Strauss, although clearly working as a team - joined in their earliest work by Jeanne Quint, whose critical contribution has largely been ignored (later Jeanne Quint Benoliel, see Quint, 1967) - do not refer to the ways in which they co-operated and co-ordinated their work. Failing to address the issues of team-working is in fact fairly wide-spread in the general literature on research methods, although there are a few notable exceptions that specifically do focus on this aspect, and we have sought to clarify our team-based approach by opting for a dialogue rather than a joint paper. Wiener's chapter in The Sage Handbook of Grounded Theory does address team-working (Wiener, 2007), drawing on her work with Strauss and others in the 1970s and 1980s. The article by Vasconcelos et al. (2012) offers an interesting example of GTM and related approaches in the field of information research, clearly involving a team of four researchers, but does not offer insights into how the team worked together.

It is now an expectation for researchers to document their methods; initially in their proposals - indicating how they intend to tackle the topic - and later in their research reports - describing what they actually did. It is important that the latter aspect is dealt with openly and honestly, describing what was actually done even if it goes against the initial plan and diverges from the textbook accounts of the method or methods employed. Such accounts need to display what I have termed 'methodological sensitivity', and for the most part theses and journal papers and other research accounts do indeed exhibit this in various ways and with varying degrees of cogency.

Glaser and Strauss used an interesting metaphor in The Discovery of Grounded Theory, discussing the ways in which effective GTM research should lead to "an armamentarium of categories and hypotheses on substantive and formal levels" $(1967,46)$; all of course drawn from and grounded in the data. The term armamentarium in this sense refers to a set of conceptual resources available to the researcher, but the original meaning is a medical term for a set of procedures, techniques, equipment, and medicines. Glaser and Strauss used the term to refer to research outcomes, but the term can also be usefully applied to research methods, tools, techniques and other resources. LIS researchers need to develop and be supported in a sustained process of awareness of available options; in some cases selecting some at the outset, but then setting these aside and adopting others as the research progresses: also adapting and varying parts of the armamentarium as they encounter novel aspects in their investigations. 
Overall 'making sense of methods' requires these sensitivities, and it is certainly encouraging that across all disciplines and fields of study there is an emphasis on researchers articulating their methodological encounters and experiences. It is, however, incumbent on the academic gatekeepers - senior academics, journal editors and reviewers, examiners, and others of their ilk - to ensure that the demand for such accounts does not become and end in itself, with researchers accounting for their work against an agenda that is driven by textbook accounts of methods and research orthodoxies that are outdated and biased towards or against specific research approaches. Extending the medical metaphor of the armamentarium, we all need to be aware that the emphasis on methods should be seen as a pharmakon, a Greek term that can mean both cure and poison. It is crucial that researchers are encouraged to discuss, learn about, and report on their methodological journey and experiences, but in a manner akin to the former, avoiding any excesses that hint at the latter.

E A-H: I think that the work of Chu, for me, shows a sensitivity to the research process; it recognises the need to select approaches that appropriately allow and support the gathering of data, rather than applying a more formulaic approach or being a servant of a specific approach. It is interesting to look at the variety of techniques and tools applied in research within LIS, and to note that this seems to be consistent with the need for such sensitivity. Simply by looking at a small number of years of research articles in the journal Library and Information Science Research it is evident that there is a constantly growing and changing application of relevant and effective strategies that allow researchers to deal with the complexity of the subject, allowing practitioner expertise and academic contributions to bring new understanding and knowledge. Your examples are also indicative of this.

You draw attention to the emergence of Grounded Theory and to Action Research, both of which have been considered by some as violating key aspects of 'real research', but more critically they do, as you point out, take us past the exhortation that research relies only on counting what can be counted. In our study (Halpin et al., 2015) we clearly describe the weaknesses in the idea of counting the number of loans and library footfall; a fallacy in relation to the value and impact of the public library. The often complex nature of library and information science requires examination of a multiplicity of factors, some of which can be researched using quantitative tools, however others, especially those involving human interaction or engagement, require at least some use of qualitative tools. I therefore have to concur with the views of both Glaser and Strauss, and Lewin, in the development of both Grounded Theory and Action Research respectively, that effective research is the important factor. This is particularly apposite in relation to LIS research oriented towards professional practice, delivery, and policy, where more often than not the researcher may also be the practitioner. As practitioners it is hard to imagine the researcher standing objectively outside the domain of study, or entering that research domain with an empty head, though as professionals they are quite able to enter with an open mind, and to research as objectively as any other researcher. 
Taking just a few examples, including some referenced by you, can indicate this clearly. Moroni (2011) in undertaking her article "Action research in the library: Methods, experiences, and a significant case" makes a very helpful observation:

Research techniques must be chosen as a function of the goal and of the examined context, but qualitative ones are usually more suited to analyze the problems in deep, and to stimulate reflections that are useful for promoting changes. (Moroni, 2011, 4)

This sentiment echoes the need for methodological sensitivity, as you have argued in this article. She observes later in her article that,

On the one hand, action research activities are reported as useful for the improvement library services, with particular reference to educational service; on the other hand, they stimulate a reflection on working processes and relational dynamics, opening new perspectives or mobilizing novel attitudes. (Moroni, 2011, 8)

Faggiolani (2011) also stresses the importance of ensuring that the selection of method or tool for research serves to provide evidence in responses to Lewin's concern to dissipate the supposed dichotomy between 'theory' and 'practice':

For this reason, the theory which has been extracted from a Grounded Theory research has a great practical and applicable worth and is highly suitable, from a methodological point of view, to research contexts which require concrete and practical results and, therefore, even today the Grounded Theory continues to be successfully applied in those fields which take into examination new phenomena: as we have seen, the method was created from the bottom - from the practical level - it was built upwards towards the theoretical and its great success lies not in its theorical (theoretical?) legitimacy, but in the results it is able to deliver. (Faggiolani, 2011, 9)

She continues as follows:

One strength of the methodology lies, in fact, in the adaptability to different applicative contexts which allows for the close examination of all those particular situations which, in the case of a uniform information collection procedure (such as a questionnaire), would be lost, creating a homogeneous but incomplete picture of the reality studied. At the same time, we have seen how such a wealth is completely in the hands of the researcher who must be able to combine scientific rigour and creativity, using a flexible but careful and well-thought out approach. (Faggiolani, 2011, 28)

For me this provides strong evidence of the value of methodological sensitivity, in action, within the library and information science community, and recognition of how this serves both theory and practice.

\section{Conclusion}

It is important to note that across the field of library and information research there is a strong and ever-developing awareness of the importance of research; not only in terms of understanding the ways in which the internet age has dramatically 
changed the research process itself and the role of LIS professionals in providing support to researchers, but also the extent to which this body of professionals themselves undertake their own research and use the findings of their colleagues and others. The recent survey by Buckley, Woods and Booth (2013) offers a wideranging and clear discussion on this topic, based on the 2013 LIRG Research Scan - including an extensive bibliography. One of the three key trends that was identified in the scan was 'action research', and other aspects included those oriented around evidence-based research that can lead to more effective practice not quite the same as GTM, but closely related.

GTM and AR need to be understood as important components of the armamentarium for LIS researchers, but it is critical that researchers understand that opting to use one or more of the available possibilities must be a considered decision; one that might need to be revised or completely jettisoned as the research develops. It is somewhat disconcerting that this message is not new, but seemingly needs to be reiterated over the years. For example in 1993 the IFLA Journal published an article by Darlene Weingand on "Grounded Theory and Qualitative Methodology" that makes many of the points we have outlined above. Perhaps the key objective of this paper has been an attempt to draw attention to the need for 'methodological sensitivity', which seems especially appropriate to the LIS community; encompassing not only the roles of experienced researchers and supervisors, and those who might be considered 'gatekeepers', but also in their crucial support for researchers in general. We have a duty to encourage and foster this sensitivity, both amongst new or inexperienced researchers and amongst colleagues and researchers more widely. We are certainly not claiming the last word on these issues, but hope that this dialogue has contributed to people's understanding of some key aspects of doing research, both within the LIS community and beyond.

\section{References}

Alemu, G., Stevens, B. Ross, P., and Chandler, J. (2015) The use of a constructivist grounded theory method to explore the role of socially-constructed metadata (Web 2.0) approaches. Qualitative and Quantitative Methods in Libraries (QQML), 4, 517-540.

Bryant, A. (2017) Grounded Theory and Grounded Theorizing: Pragmatism in Research Practice. New York: Oxford University Press

Bryant, A., Black, A., Land, F. and Porra, J. (2013) Information systems history: What is history? What is IS history? What IS history? ... and why even bother with history? Journal of Information Technology, 28(1), 1-17.

Bryant, A., and Charmaz, K. (eds.) (2007a) The Sage Handbook of Grounded Theory. London: SAGE.

Bryant, A., and Charmaz, K. (2007b) Grounded Theory in historical perspective: An epistemological account. In: Bryant, A., and Charmaz, K. (eds.) The Sage Handbook of Grounded Theory. London: Sage. 
Buckley Woods, H., and Booth, A. (2013) What is the current state of practitioner research? The 2013 LIRG Research Scan. Library and Information Research, 37(116), 2-22.

Cameron, W. B. (1963). Informal sociology: a casual introduction to sociological thinking. New York: Random House

Charmaz, K. (2006, 2014) Constructing Grounded Theory. London: SAGE.

Chu, H. (2015) Research methods in library and information science: A content analysis. Library \& Information Science Research, 37(1), 36-41. URL:

http://www.sciencedirect.com/science/article/pii/S0740818815000109 [accessed 07/03/2017].

Dey, I. (1993) Qualitative Data Analysis. London: Routledge.

Glaser, B. (1978) Theoretical sensitivity: advances in the methodology of grounded theory. Mill Valley, CA: Sociology Press

Glaser, B. and A. Strauss (1967) The Discovery of Grounded Theory: Strategies for Qualitative Research. London: Aldine.

Guba, E. G., \& Lincoln, Y. S. (1998) Competing paradigms in qualitative research. In: Denzin, N. K., and Lincoln, Y. S. (eds.). The landscape of qualitative research: Theories and issues. 195-220. Thousand Oaks, CA: Sage.

Faggiolani, C., (2011) Perceived identity: applying Grounded Theory in libraries. Italian Journal of Library and Information Science, 2(1). URL: www.jlis.it/article/view/4592 [accessed 07/03/2017].

Halpin, E., Rankin, C., Chapman, E.L. and Walker, C. (2015) Measuring the value of public libraries in the digital age: What the power people need to know. Journal of Librarianship and Information Science, 47(1), 30-42.

Lewin, K. (1946) Action Research and minority problems. Journal of Social Issues, 2(4), 34-46.

MacLennan, A. (2012) Immersed in cyberspace: an evaluation of a grounded theory approach to a study of user preferences. Library and Information Research, 36(112), 55-71.

Mansourian, Y. (2006) Adoption of grounded theory in LIS research. New Library World, 107(1228/1229), 386-402.

Moroni, I. (2011) Action Research in the library: Method, experiences, and a significant case. Italian Journal of Library and Information Science, 2(2), URL: www.jlis.it/article/view/4702 [accessed 07/03/2017].

Pickard, A. J. (2007) Research methods in information. London: Facet.

Quint, J. (1967) The Nurse and the Dying Patient. London: Macmillan

Reason, P. and Bradbury, H. (eds.) (2013) The Sage Handbook of Action

Research, $2^{\text {nd }}$ edition. London: SAGE.

Strauss, A. and Corbin, J. (1990, 1998) Basics of Qualitative Research:

Techniques and Procedures for Developing Grounded Theory. London: SAGE. 
Vasconcelos, A., Sen, B., Rosa, A., and Ellis, D. (2012) Elaborations of grounded theory in information research: arenas/social worlds theory, discourse and situational analysis. Library and Information Research, 36(112), 120-146.

Weingand, D. (1993) Grounded Theory and qualitative methodology. IFLA Journal, 19(1), 17-26.

Wiener, C. (2007) Making teams work in conducting Grounded Theory. In: Bryant, A., and Charmaz, K. (eds.) The Sage Handbook of Grounded Theory. London: Sage.

\section{Open access and copyright}

Library and Information Research is an open access journal. A freely available copy of this paper may be downloaded from the journal's website:

http://www.lirgjournal.org.uk/

Copyright and associated moral rights in works published in Library and Information Research are retained by the author(s) but this paper may be used freely, with proper attribution, in educational and other non-commercial settings. 